\title{
Del dominio de los fundamentos de la comedia de buenas costumbres a la práctica exitosa: Contigo pan y cebolla (1833) de Manuel Eduardo de Gorostiza
}

\author{
From the mastery of the foundations of the comedy \\ of good manners to the succesful practice: \\ Contigo pan y cebolla (1833) \\ by Manuel Eduardo de Gorostiza
}

\author{
Víctor Cantero García \\ Universidad Pablo de Olavide \\ cantero91@hotmail.com
}

RESUMEN: Hasta el presente, tanto los estudiosos del teatro español del siglo XVIII como la crítica teatral, han considerado a Manuel Eduardo de Gorostiza (1789-1857) un dramaturgo menor. En la presente colaboración pretendemos demostrar que tal aserto no se atiene a la verdad. Mediante un estudio contrastivo entre El señorito mimado (1787) de Tomás de Iriarte y Contigo pan y cebolla (1833) de Gorostiza, evidenciamos que éste alcanzó renombre como autor de comedias de buenas costumbres por méritos propios, y no por ser un mero seguidor de las pautas de la comedia neoclásica establecidas por Nicolás Fernández de Moratín y afianzadas por Tomás de Iriarte. En esencia, los contenidos y argumentos expuestos en el presente artículo son una prueba manifiesta de que Gorostiza dio a luz comedias que alcanzaron un éxito de público y crítica que le hacen merecedor de ocupar un puesto relevante tanto entre los ilustrados liberales de origen hispano como entre los autores de comedias de buenas costumbres.

PALABRAS CLAVE:
comedia;
buenas costumbres;
teatro neoclásico;
análisis contrastivo.

ABSTRACT: Until now, eighteenth-century Spanish the-
ater scholars and critics have considered Manuel Edu-
ardo de Gorostiza (1789-1857) a minor playwright. In
the present collaboration we intend to demonstrate
that such an assertion does not conform to the truth.
Through a contrastive study between El señorito mi- 
KEYWORDS:

Comedy;

Good manners;

Neoclasiccal theater;

Constrastive analysis. mado (1787) by Tomás de Iriarte and Contigo pan y cebolla (1833) by Gorostiza, we mean to show that the latter one became a renowned author of comedies of good manners on his own merits and not for being a mere follower of the guidelines of the neoclassical comedy established by Nicolás Fernandez de Moratín and consolidated by Tomás de Iriarte. In essence, the contents and arguments set forth in this article are clear evidence that Gorostiza conceived comedies that achieved a public and critical acclaim and made him worthy of occupying a relevant position both among the enlightened liberals of Hispanic origin as well as among the authors of comedies of good manners.

\section{Introducción}

Cuando en los foros académicos en los que se debaten los avatares de la Ilamada comedia de buenas costumbres, género dramático que se prodigó en España en el siglo XVIII y primeras décadas del XIX, se menciona a Manuel Eduardo de Gorostiza (Veracruz, México, 1789-Tacubaya, Ciudad de México, México, 1851) como dramaturgo menor, surgido y formado a la sombra de Leandro Fernández de Moratín y Tomás de Iriarte, no se dice la verdad, pues Gorostiza fue un dramaturgo con entidad propia, con reconocida solvencia y con capacidad e ingenio para escribir piezas que nada tienen que envidiar a las piezas que sus homólogos hispanos dieron a la comedia neoclásica. Este es el propósito de la presente colaboración, a saber: demostrar que Gorostiza no fue un servil imitador ni un continuador oportunista de los dictados dramáticos de quienes le precedieron, sino un autor capaz de componer obras originales con las que alcanzó un grado de éxito de público y crítica que le hacen acreedor de un lugar destacado en la dramaturgia española de su época por méritos propios.

En modo alguno nos hubiéramos atrevido a formular esta afirmación y a afrontar el reto de demostrarla, de no contar de entrada con opiniones cualificadas que apuntasen en este sentido. Tal es el caso del párrafo final de la crítica que Mariano José de Larra dedica a Contigo pan y cebolla (1833), que es considerada como comedia emblemática de nuestro autor: 
A pesar de estas observaciones, que no podemos menos de hacer, nos complacemos en repetir que es mayor la suma de las bellezas que la de los defectos de la comedia. El señor Gorostiza ha adquirido un nuevo laurel, y nosotros quisiéramos que la obligación del periodista se limitara a alabar: mucho nos daría que hacer aun en este caso esta composición dramática. En cuanto a la representación, podemos asegurar que no nos acordamos haber visto en Madrid nada mejor desempeñado en este género (Larra 1833: 702). ${ }^{1}$

Este es, por tanto, nuestro punto de partida. $Y$ dado que en toda disertación que se precie de ser coherente lo que se afirma debe demostrarse con los hechos, nuestro trabajo se estructura con base en el principio elemental de toda demostración empírica: los hechos que se afirman y fundamentan con argumentos teóricos han de ser demostrados con pruebas prácticas para ser admitidos como tales. En este sentido, el esquema estructural de nuestro estudio se configura del siguiente modo: partimos del análisis de aquellos elementos sustanciales que confieren a Gorostiza el estatus de conocedor concienzudo y reputado de todo lo que afecta a la singular problemática de la dramaturgia neoclásica española, continuamos evidenciando cómo nuestro autor elabora su propia concepción de la comedia neoclásica, a partir de la preceptiva dramática en vigor, y concluimos mostrando cómo lleva a la práctica dicha concepción en su obra Contigo pan y cebolla, eliminando los aspectos que él censura en otros dramaturgos y potenciando aquellos que según su criterio mejoran la factura de sus obras.

Acorde con esta forma lógica de proceder, dedicamos un primer apartado de nuestro artículo a poner de manifiesto cuáles son los motivos que hacen que Gorostiza se incline por la profesión de dramaturgo. En segundo lugar traemos a colación todos los argumentos necesarios que acreditan a nuestro escritor como conocedor de primera mano del "paño" con el que habría de lidiar en sus comedias. En otras palabras, intentamos justificar que su opción por el teatro viene precedida de un conocimiento profundo y detallado del panorama teatral español del siglo XVIII. En un

1 En este mismo artículo, Larra precisa: "En el acto cuarto, que parece un acto de otra comedia" (791), en clara alusión al rompimiento por parte de Gorostiza de las unidades clásicas de la comedia, con lo que implícitamente señala que nuestro autor se adelanta a la estética romántica. 
tercer momento damos el salto de los dichos a los hechos; para probar que en este caso del dicho al hecho no media un gran trecho realizamos un estudio contrastivo de dos comedias representativas del género denominado comedia de buenas costumbres: El señorito mimado (1788) de Tomás de Iriarte y Contigo pan y cebolla (1833) de Gorostiza. En este análisis procedemos a demostrar cómo nuestro dramaturgo practica su propia concepción del arte dramático; comprobamos hasta qué punto supera el modelo de la comedia irartiana y elabora una pieza dramática que se libera del corsé de la preceptiva neoclásica y anticipa la comedia romántica. Damos fin a nuestro trabajo con el apartado dedicado a las conclusiones.

\section{Análisis de los factores personales, sociales y políticos que confieren a Gorostiza una posición relevante}

Al estudiar la compleja situación sociopolítica que se vivía en España durante el gobierno absolutista de Fernando VII, en el trienio liberal (18201823) y en la llamada Década Ominosa, nos olvidamos de que en medio de tanto conflicto político hubo lugar para el surgimiento de personalidades destacadas como la de Manuel Eduardo de Gorostiza. Sin embargo, hacerse un hueco en ese entramado sociopolítico no era tarea sencilla, a menos que se contase con una buena carta de presentación y adecuados antecedentes. Gorostiza contaba con ellos. Para empezar, Pedro Fernández de Gorostiza, su padre, era amigo y familiar del segundo conde de Revillagiedo, nombrado virrey de México. En el viaje de dicho conde hacia la Nueva España fue acompañado por el padre de nuestro autor, quien a la sazón viajaba para tomar posesión como gobernador de Veracruz, brigadier e inspector general de las tropas del reino en Nueva España. Asentado en Veracruz, don Pedro contrae matrimonio con doña Rosario Cepeda y Mayo, dama gaditana, culta, ilustre y emparentada con santa Teresa de Jesús. Fallece el padre en 1794 y la madre regresa a España con el objeto de posicionar profesionalmente a sus hijos. En un principio los dos hermanos mayores pasan a ser pajes en la corte de Carlos IV. Con el tiempo, Francisco, el de más edad, se hace cargo del mayorazgo familiar y Pedro Ángel se distingue como matemático y literato notable. En cuanto a Manuel Eduardo, por ser el hijo menor de una familia distinguida le co- 
rresponde ingresar en la vida eclesiástica. Él se opone a tal destino y opta por la milicia, influido por la profesión paterna. Y ésta hubiera sido la suya de no ser por el percance que la truncó, al que aludiremos unas líneas más adelante. Bien sabía nuestro autor que para que su nombre resonara en los ambientes sociales elitistas, así como en las tertulias y foros de debate, no podía conformarse con alcanzar el rango de sargento. Se aplicó como excelente alumno en la Academia Militar y al graduarse lo hizo como capitán de granaderos. Avanzado 1808, los franceses penetran en España y se produce el alzamiento popular del 2 de mayo. Gorostiza participa en la batalla de Bailén y un bayonetazo le atraviesa el pecho. Por fortuna la herida no fue letal, pero lo postró convaleciente por unos meses. Repuesto del trance y acabada la guerra, abandona el hospital militar con la condición de coronel. Una credencial que le abría las puertas de los selectos círculos aristocráticos.

Llegados a este punto nos preguntamos: ¿qué sucedió en la vida de Gorostiza para que cambiase el uniforme por la pluma? Su inclinación por las letras es consecuencia de sus largos meses de convalecencia. Si ya desde niño sintió interés por las bellas letras, éste se incrementó por las muchas horas dedicadas al estudio, a la lectura y a la práctica poética durante su estancia hospitalaria. Aquí radica el germen de su vocación literaria, la cual comparte con su dedicación a la política. Sabe Gorostiza que el único modo de hacerse oír en las instancias literarias y políticas es contar con amistades que reconozcan su valía personal y que le faciliten el acceso a las tertulias y a los círculos políticos. Esta entrada de nuestro autor a la vida pública llega justo cuando en España se respiran los aires reformistas emanados del talante liberal que se desprende de la Constitución de 1812, sancionada en Cádiz. El liberalismo gaditano y el aperturismo de la Constitución de 1812 (denominada "La Pepa") impregnan el corazón y estimulan la mente de Gorostiza. En Cádiz conoce a Alcalá Galiano, Martínez de la Rosa, Quintana, entre otros, y comparte nostalgias mexicanas con Miguel Ramón Arizpe, antes de ser éste encarcelado por el rey felón. Conoce en la capital gaditana a José Mariano de Michelena, que será su gran amigo y valedor ante el gobierno mexicano. Entabla amistad con Guillermo Rocafuerte y muchos otros diputados de las cortes de Cádiz. En suma, nuestro autor no es un joven anónimo, sino un político 
liberal apreciado en los escenarios políticos emanados del nuevo marco constitucional vigente. En otras palabras: "Manuel Eduardo de Gorostiza es un modelo del tipo de hombre propio de aquellos tiempos. Mezcla de peninsular y americano, mestizo de dos culturas y de dos pasados, síntesis y arquetipo de fidelidades y entregas compartidas, que cada uno supo vivir y protagonizar a su manera" (Ortuño Martínez 1988: 106).

En suma, se trata de un hombre ilustrado a la altura de lo que fueron coetáneos suyos como su amigo Francisco Javier Mina, ambos enfrentados a los abusos del poder absolutista de Fernando VII, motivo por el que sufrieron destierro. Se puede decir más alto, pero no más claro, Gorostiza es un liberal convencido que sufre las consecuencias de la vuelta de los Borbones al trono, tras el trienio liberal. Después de la ejecución de Riego el 7 de octubre de 1823, se teme lo peor y para evitarlo:

A principios de 1824 se ve obligado a huir de España, con su esposa, que vestida de hombre, viaja con él a caballo hasta alcanzar la frontera francesa. Después de recorrer varias ciudades europeas se radica en Londres. Desde allí ofrece sus servicios al recién estrenado Gobierno Mexicano en una carta literaria admirable y a nuestro juicio moralmente veraz, en la cual confiesa su condición de ciudadano liberal y siempre dispuesto a servir a la causa de la libertad europea (Suarez Radillo 1984: 103).

$\mathrm{Y}$ es justo durante su estancia en Londres cuando traba amistad con Thomas Campbell, poeta, historiador y periodista escocés, quien más tarde sería el editor de sus obras. De estos lazos amistosos nos da cuenta Cyrus Redding en el capítulo que dedica a Gorostiza, dentro de la extensa obra destinada a Campbell titulada Reminiscentes and Memorias of Thomas Campbell (1860): "Gorostiza was a man of the world, well read in the whole circle of Spanish literature; of easy manners, and rather a vivacious temperament. He became an exile under Ferdinand VII. Whit small pecuniary means, but a truly noble mind, Gorostiza fled into France, and doubting there of his security under the rule of the king whom foreigners had replaced, he crossed the channel to London" (Redding 1860: 318-319). ${ }^{2}$

2 [Gorostiza era un hombre de mundo, bien leído en todo el círculo de la literatura española; de modales fáciles y temperamento bastante vivaz. Se convirtió en un exiliado bajo Fernando VII. Con pequeños medios pecuniarios, pero con una mente 
En suma, Gorostiza es persona de convicciones y principios bien conocidos tanto por sus amistades como por sus detractores. Dejado atrás el suelo hispano, escribe con libertad sus intenciones en cuanto a su actuación en la esfera pública:

Desde entonces, ni he tenido otro carácter público, ni lo he solicitado. Sin embargo, he sido bastante dichoso por haber podido, desde mi rincón, servir la causa de la libertad europea, ya como mero ciudadano, ya como escritor. Debo también a ambas circunstancias, la honra de que se me haya proscrito de mi tierra adoptiva, y de que se me haya confiscado cuanto tenía [...] Mexicano pues, y rotos los vínculos que me ligaban a la que fue cuna de mis padres, mi deber y mis principios, conjuntamente me impelen a ofrecer a la República mi homenaje y mis estériles votos, aunque ardentísimos, por su futura prosperidad (Gorostiza citado en María y Campos 1959: 59-60).

Vuelve Gorostiza del exilio, y se incorpora a la vida política y social de Madrid del momento, gracias a su actividad como periodista. Comienza como colaborador de la Crónica Científica, Literaria y Política, periódico dirigido por José Joaquín de Mora, a quien sustituye en el cargo durante la larga estancia de éste en París, a la par que añade el apelativo de $E I$ Constitucional a este rotativo. Frecuenta las tertulias y clubes literarios de la capital, tales como Lorenzini, ubicado en la Puerta del Sol, y La fontana de oro, en la esquina de la Carrera de San Jerónimo con la calle de la Victoria. En resumen, las jornadas revolucionarias de marzo de 1820 coinciden con un Gorostiza en plenitud de facultades y ubicado por las circunstancias políticas en una posición relevante. Justo en pleno trienio liberal cuenta con treinta y tres años y experiencia teatral adquirida, fama y reconocimiento, pues para entonces ya ha publicado casi todas sus comedias originales: Indulgencia para todos (1818); Las costumbres de antaño (1818 y 1833); Tal para cual, las mujeres y los hombres, Don Dieguito (1820); Madrid, virtud y patriotismo o el primero de mayo de 1820 (1821), dejando para 1833 la que sería su comedia más conocida y exitosa: Contigo pan y cebolla.

verdaderamente noble, Gorostiza huyó a Francia, y dudando de su seguridad bajo el gobierno del rey a quien los extranjeros habían reemplazado, cruzó el canal hacia Londres]. La traducción es propia. 


\section{Hacia una concepción propia del arte dramático: el tránsito de la teoría a la praxis de la comedia neoclásica}

Despejadas las posibles dudas sobre la relevancia de la personalidad de Gorostiza, así como conocidos los motivos de su inclinación por las letras, procede que nos concentremos en considerar cuáles son los argumentos que respaldan su ubicación como dramaturgo de prestigio en el panorama teatral español del siglo XVIII. Con tal propósito la secuencia de nuestra exposición sigue una progresión deductiva: partimos de los conocimientos previos que nuestro autor demuestra tener sobre el teatro español, continuamos con la presentación de los aspectos de aquél que Gorostiza censura de un modo razonado, seguimos con la descripción de los elementos del drama y de la comedia neoclásicos que él asume y terminamos exponiendo su propia concepción del arte dramático, como paso previo a la praxis de la comedia.

Gorostiza efectúa un profundo estudio de la realidad del teatro hispano de los siglos anteriores para demostrar que los males que aquejan a la escena española proceden de antaño. Siendo cierto que el dominio del arte poético está en los cimientos de toda obra dramática, nuestro autor critica los perjuicios que los excesos del culteranismo causaron a los cánones poéticos heredados del Renacimiento y cultivados en sus obras por Lope de Vega y Calderón, entre otros. Su oposición al modelo poético de Góngora la expresa nuestro autor en su artículo "Culteranismo", y centra sus críticas al mismo en el hecho de que los culteranos "se desviaron del único sendero que aconsejaban la razón y la filosofía, y buscaron un nuevo camino que les condujese a la celebridad y creyeron hallarle mejor, a medida que se extraviaban más" (Gorostiza 1959a: 398). ${ }^{3}$ Un razonamiento que reitera en su artículo "Decline of Ancient Theatre": 4 "however painful it may be to acknowledge, men of great genius, and capable of adding fresh glory to literature, have been the first to desert the path which

3 Al respecto hemos de señalar que la oposición "culteranismo" frente a "conceptismo" está hoy superada, pues desde la Agudeza (1648), de Gracián, Góngora es un maestro del concepto.

4 El cual forma parte de la serie de cuatro artículos que, bajo el título genérico On the Modern Spanish Thatre, publicó en 1824 durante su exilio londinense. 
reason and philosophy suggest, and to pervert the taste the multitude, ever prompt to follow in the train of novelty" (Gorostiza 1824a: 398). ${ }^{5}$ Gorostiza critica el hecho de que los excesos culteranos pervirtieran el gusto del público que asistía al teatro, el cual se dejó arrastrar por las extravagancias de la poesía gongorina y, debido a su ignorancia, atribuyó tales excesos a la grandeza del ingenio de los nuevos poetas. Es decir, que Gorostiza tacha a Góngora de culterano. En este sentido, censura que la escena española diese la espalda a las comedias de enredo y de capa y espada de corte lopesco y rindiese pleitesía al modelo cómico barroco cargado de exageraciones y falto de verosimilitud. Nuestro dramaturgo, como buen ilustrado, se opone a todo tipo de excentricidad e incoherencia, pues tal como señala Felipe Reyes Palacios, Gorostiza en la loa final de su comedia Las costumbres de antaño (1818) "ya exhibe de manera contundente su ideología ilustrada, orgullosa de los logros del presente y refractaria a toda nostalgia del pasado, aunque en el discurso teórico de los artículos londinenses se muestre después respetuoso de las peculiaridades vernáculas del teatro del Siglo de Oro y de otras tradiciones nacionalistas" (Reyes Palacios 2009: 12).

Inducido por su talante culto y su pensamiento ilustrado, Gorostiza extiende sus críticas a los autos sacramentales calderonianos, pues "Calderón, al mismo tiempo que se mofaba en la mayor parte de sus comedias familiares de todo aquel que hablaba culto, y que ponía en cada instante en boca de sus graciosos las alusiones más picantes sobre Góngora y su secretario, caía, sin embargo, en iguales o superiores extravagancias así que quería elevarse un poco" (Gorostiza 1959a: 404). En su opinión, los autos sacramentales son piezas que mantienen verdaderas controversias sobre las cuestiones más abstractas y en ellos se confunden los entes morales con los seres reales. Equivocaciones que prueban el pésimo estado en que se encontraba el teatro español en pleno siglo XVII. Tras el declive

5 [Por doloroso que sea reconocer, los hombres de gran genio, y capaces de agregar nueva gloria a la literatura, han sido los primeros en abandonar el camino que sugieren la razón y la filosofía, y en pervertir el gusto de la multitud, siempre incitando a seguir el tren de la novedad]. Todas las traducciones de los artículos de Gorostiza escritos en inglés son propias. 
de los Austrias, la escena española queda huérfana hasta la llegada de los Borbones y con ellos se inicia en España el periodo Ilustrado.

Precisa Gorostiza cuáles pueden ser los motivos por los que el modelo del teatro neoclásico francés es adoptado en nuestra escena sin el menor reparo. La primera razón estriba en la habilidad de los dramaturgos franceses para apropiarse de los dramas originales hispanos y hacerlos pasar como suyos. Tal es el caso de Corneille, con Le Cid (1636), una recreación de Las Mocedades del Cid (1605-1615) de Guillén de Castro y Le Mentieur (1643), una versión francesa de La verdad sospechosa (1636) de Juan Ruiz de Alarcón; o de Moliere con El Don Juan (1665), pieza en la que reproduce dicho mito hispano. De esta guisa, y sin que el público no iniciado se percatase, entra en la escena española el refinado gusto francés. Introducción que viene propiciada, y ésta es la segunda razón, por la fundación de la Real Academia de la Lengua por Felipe IV en 1714, a imitación de la que ya existía en París. No tardarán, añade Gorostiza, en surgir los admiradores del modelo dramático francés, que con sus normas y preceptivas intenten amoldar al teatro español los cánones del recién estrenado neoclasicismo. Y el primero de ellos será Ignacio de Luzán, "one of the most learned men and accurate writers of his time, and moreover, an elegant lyric poet, gave the most decided blow to the Spanish literature of the seventeenth century" (Gorostiza 1824b: 503). ${ }^{6}$

Pone fin nuestro autor a su demostración de sus conocimientos del teatro español con sus alusiones al Molière español: Nicolás Fernández de Moratín, quien a su juicio fue el primero en hacer teatro a la manera de Terencio y de Molière y por ende asentar en suelo hispano el modelo dramático neoclásico. Un patrón que en lo que atañe a la comedia —que es el género que interesa a Gorostiza - considera que ésta "debe reunir las cualidades de utilidad y deleite, persuadido de que sería culpable el poeta dramático que no se proponga otro fin en sus composiciones que el de entretener dos horas al público sin enseñarle nada, reduciendo todo el interés de una pieza de teatro al que pueda producir una sinfonía" (Fernández de Moratín 1944: 320). Toma buena nota Gorostiza tanto de las directrices

6 [Uno de los hombres más sabios y uno de los más agudos escritores de su tiempo, y además, un elegante poeta lírico, dio el empujón decisivo a la literatura española del siglo XVII]. 
que Luzán expone en su Poética, como de las propuestas moratinianas sobre los requisitos que han de cumplir las comedias, pero las pone en entredicho por conllevar una intolerancia y un radicalismo extremos:

Los modelos fueron siempre antes que las reglas. Aristóteles sacó de Sófocles y Menandro sus mejores preceptos sobre la tragedia y la comedia [...] Hay que estudiar continuamente todas aquellas obras maestras que honran al entendimiento humano para ensanchar por su medio el círculo de nuestras ideas. Hay que dirigirse por aquellas reglas hijas de la razón y la filosofía, que pueden conducirnos con acierto al conocimiento de lo bueno y de lo bello, pero entre esto y copiar servilmente lo que otros hicieron o quisieron que se hiciese, es notable diferencia (Gorostiza 1959b: 408).

Una intolerancia y un radicalismo que "en una primera aproximación pueden resultar sorprendentes o repugnantes, pero que se legitiman (a la vista de sus teóricos) por estar basadas en la tradición de la antigüedad grecolatina, en la razón y en las exigencias de la psicología del destinatario de la literatura: tres ejes de coordenadas supuestamente fijos y con respecto a los cuales el discurso neoclásico se define como de trayectoria única e invariable" (Carnero 1997: 8).

Comprobado el dominio con el que Gorostiza cuenta en relación con los avatares del teatro español en su tránsito del Siglo de Oro al canon neoclásico, procedemos a evidenciar cómo se sirvió de aquél para confeccionar su propia concepción del arte dramático, la cual pondrá en práctica en sus comedias. Toma nuestro autor de Luciano Francisco Comella, a quien considera el precursor del teatro neoclásico español, la idea de que la comedia ha de poner en escena vicios y defectos, a fin de que el público se percate de ellos y los pueda corregir en sus vidas. Éste es el propósito común que ha de determinar la trama de las "comedias de buenas costumbres", de aquí que Gorostiza tome como referente para la elaboración de las suyas El viejo y la niña (1786) de Leandro Fernández de Moratín. En esta pieza encuentra pasajes muy hermosos, fascinantes y llamativos. En ella el diálogo es suficientemente animado y enérgico y los caracteres más esenciales para la organización de la intriga se han perfilado de forma admirable, tanto en su concepción como en su ejecución. Un referente que completa con su aprecio por El sí de las niñas (1806), pieza en la que 
encuentra una trama netamente romántica, justo lo que él buscaba para dar forma a Contigo pan y cebolla (1833).

Con todos estos elementos en mente, Gorostiza acuña su propia doctrina sobre el arte dramático, basada en los siguientes principios teóricos. El primero y elemental es que todo autor ha de proponerse que la representación de sus obras logre la mejora y el pulimento de las costumbres públicas, ya que al mismo tiempo esas costumbres influyen sobre las tintas con las que las escenas se pintan. Para lograrlo ha de poner en escena un cuadro que esté ya en la naturaleza de las cosas, pues si es inverosímil o representa hábitos desconocidos no logrará el fin moral que pretende toda comedia. De aquí que el teatro deba de ser un espejo de las costumbres de las naciones cultas y un termómetro de la civilización. Por ello el pueblo ha de tener su propio teatro y que en él se retraten las facciones que le son más propias, con los colores que también sean peculiares. Un espejo en el que el espectador pueda reconocerse, pues de lo contrario no sirve para nada que asista al teatro. El segundo es la lógica consecuencia del anterior y en él Gorostiza rechaza el hermético corsé de las reglas impuestas por la preceptiva neoclásica. Dado que el teatro ha de poner en escena los vicios y costumbres de las personas, lo primero a tener en cuenta por el autor han de ser los modelos o los caracteres que lleven a las tablas esos vicios y costumbres, dejando como secundario el respeto a las reglas. En el teatro tan sólo son válidas aquellas reglas que sean hijas de la razón y de la filosofía, las cuales pueden conducirnos con acierto al conocimiento de lo bello y de lo bueno. De nada sirve la copia servil de lo que otros hicieron. Cada autor ha de ser original en lo que hace, pues el teatro tan sólo cobra vida cuando el autor es capaz de concitar a las demás artes al objeto de que la ilusión creada en la escena sea para el espectador lo más completa posible.

Únicamente cuando sobre las tablas hay más verdad dicha con más agrado, la pieza logra su fin. En definitiva, Gorostiza filtra y hace suyos los preceptos moratinianos sobre la comedia y los transforma en recomendaciones prácticas, que es en sustancia lo que el propio Moratín predica: "en la comedia se recomienda la virtud haciéndola amable, como efectivamente lo es, pintando en otros hombres pasiones generosas o tiernas, que haciéndolos superiores a todo otro interés menos laudable, los determinen 
a proceder en las varias circunstancias de la vida según los principios de la justicia, de la prudencia, de la humildad y del honor lo piden" (Fernández de Moratín 1944: 221).

\section{Estudio contrastivo de El señorito mimado (1788) y Contigo pan y cebolla (1833)}

Si bien Gorostiza sigue a Leandro Fernández de Moratín en lo que respecta a los aspectos teóricos de la "comedia de buenas costumbres", para los prácticos se inclina en tomar como modelo a Tomás de Iriarte, y sigue sus pasos a la hora de componer su comedia más exitosa: Contigo pan y cebolla (1833). La primera evidencia de que lo que aquí se dice es cierto nos la proporciona el propio Gorostiza cuando en el artículo segundo de la serie publicada en The New Monthly Magazine, y en relación con el lugar que Iriarte ocupa en la prelación de los dramaturgos neoclásicos españoles, señala:

After the Elder Moratin we meet not one deserving of remark before Don Thomas Yriarte, son renowned for his lierary fables, and his antimusical poem "Music", which obteined him so many falttering compliments from Metastasio. This writer produced some very good comedies, which have manteined an honourable repute on the stage. One of these, "El señorito Mimado" (the Spoiled Child) represents with striking accuracy the social results of a too indulgent, or, in other words, a niglected education. The characters of the mother and the son are admirable (Gorostiza 1824b: 505). ${ }^{7}$

Una mención a El señorito mimado que en modo alguno es fortuita, pues, como demostraremos en este apartado, Gorostiza tiene bien presente el texto irartiano a la hora de componer Contigo pan y cebolla, y no sólo en cuanto a la similitud de la trama: Iriarte nos presenta al joven

7 [Después del ya anciano Moratín no encontramos a nadie que merezca ser nombrado, a no ser Don Tomás de Iriarte, famoso por sus fábulas literarias que le propinaron tantos elogios y halagos por parte de Metastasio. Escribió algunas buenas comedias, que le han proporcionado una memorable reputación sobre la escena. Una de ellas, El señorito mimado que presenta con tal claridad las consecuencias sociales de una educación negligente de un hijo por parte de su padre. Los caracteres de la madre y el hijo son admirables]. 
Mariano, un señorito mimado, imprudente, superficial, indócil y de estragada conducta, que trae de cabeza a don Cristóbal, su tío y tutor, hombre recto, franco y activo, mientras que Gorostiza se concentra en describir las locuras románticas de Matilde, otra señorita mimada y alejada de la dura realidad, que es un continuo quebradero de cabeza para don Pedro, su padre; sino porque existe otra serie de semejanzas entre ambas obras, de las que nos ocupamos en esta sección.

Otro de los indicios que nos cercioran de que Gorostiza no sólo se había leído y estudiado las comedias de Iriarte, sino que conocía la denominada "filosofía sensista observacional" ${ }^{8}$ de Etinne Bonot de Condillac —en la que Iriarte asienta su concepción dramática - nos viene de la amistad que Gorostiza mantenía con José Joaquín de Mora, pues "Mora sigue la teoría de Condillac y confía como Jovellanos o Pedro María Olavide en la natural propensión de las sociedades hacia el buen gusto y la ilustración universal, que en el terreno del arte dramático han cristalizado en la fórmula clásica" (Rodríguez 1999: 252). A través de Mora, Gorostiza hace suyos los postulados de la filosofía sensista, así como el propósito de convertir a las comedias en escenificaciones del buen gusto "pues como el buen gusto procede de la cultura de nuestras facultades intelectuales, se debe creer que hay en la sociedad una tendencia hacia su propagación, así como la hay hacia la ilustración universal, que por poco favorables que sean las circunstancias políticas de la nación, estas progresen más o menos bastante" (Mora 1819: 5). Por si estas razones no fueran suficientes para convencernos de que Gorostiza conocía bien El señorito mimado, María Magdalena Álvarez Franco añade una más. En su tesis doctoral EI recurso al engaño en el teatro neoclásico español, la especialista se dedica a la ubicación puntual del engaño en los textos teatrales (2013: 347-511). Sobre esta cuestión precisa que en el corpus de textos que le ha servido de base para estudiar el engaño se encuentra El señorito mimado (1789)

\footnotetext{
8 El sensismo observacional como sistema filosófico implica admitir que las sensaciones son la única fuente de conocimiento y que ellas son un reflejo de la realidad objetiva. Los elementos del credo sensista están presentes en la Poética de Luzán, texto del que emanan las preceptivas dramáticas neoclásicas, las cuales abogan por que en las comedias se representen hechos reales y particulares, captados por el ser humano a través de las sensaciones.
} 
de Iriarte y Contigo pan y cebolla (1833) de Gorostiza. Ambas piezas son comedias de buenas costumbres entre las cuales se aprecia clara similitud en cuanto a los temas y engaños que ambos autores ingeniaron para hacer verosímil la acción que en las dos obras se desarrolla.

Tras exponer estos argumentos estamos ya en disposición de comenzar el análisis contrastivo. Lo hacemos con el objeto de comprobar hasta qué punto la pieza de Gorostiza sigue el patrón dramático pautado por Iriarte en la suya y en qué aspectos nuestro autor se aparta del mismo en Contigo pan y cebolla, que es una comedia cercana al teatro prerromántico y es "fruto de la inflexibilidad de los preceptistas neoclásicos, la cual espolea y estimula el desenvolvimiento del estilo romántico" (Usigli 2015). Teniendo presente que Iriarte aplica en El señorito mimado el molde dramático elaborado por Nicolás Fernández de Moratín en La Petimetra (1762) y que Gorostiza tiene en mente el referente dramático de El sí de las niñas (1801) de Leandro Fernández de Moratín —-filtrado por Iriarte en El señorito mimado - para componer Contigo pan y cebolla, lo que aquí mostramos es la habilidad de nuestro autor para aprovechar los ingredientes netamente románticos que se atisban en El sí de las niñas (1801) y el armazón puramente neoclásico sobre el que Iriarte confecciona El señorito mimado para redactar una comedia de tintes románticos, al igual que lo eran las novelas sentimentales y lacrimosas que leían las jovencitas casaderas de la época. Un colorido romántico que se aprecia en el siguiente comentario que Gorostiza hace sobre El sí de las niñas (1801): "the passion of love throughtout his dramatic works and to doubt his hability to portray a geunine picture of that kind. How agreeble, then, was the surprise of the public, on finding in this instance a plot entirely romantic, and a pair of lovers as tender and as passionate as are to be found within the verge of rationality" (Gorostiza 1824c: $91-91) .^{9}$

9 [La pasión del amor a lo largo de sus obras dramáticas y sin duda su habilidad para pintar una imagen genuina de ese tipo. Cuán agradable, entonces, fue la sorpresa del público al encontrar en este caso una trama completamente romántica y un par de amantes tan tiernos y apasionados como los que se encuentran al borde de la racionalidad]. 


\subsection{Semejanzas y diferencias en la organización de la intriga y caracterización de los personajes}

Siendo cierto que los ilustrados "rompieron con la forma de concebir el teatro que tenían los dramáticos barrocos y defendieron un teatro que conforme a una nueva preceptiva, se ajustase a la reglas clásicas, cumplía con las unidades dramáticas, se ajustaba a la verosimilitud y el decoro y contenía crítica social y didactismo para mejorar a la sociedad" (Roso 2016: 163); no es menos cierto que Gorostiza supo apartarse del rigor de las normas neoclásicas para construir en Contigo pan y cebolla un claro antecedente de la comedia romántica a partir del arquetipo establecido por El señorito mimado. La trama de esta comedia en tres actos y verso es la siguiente: cuando don Cristóbal, indiano acaudalado, regresa de su periplo halla que su sobrino don Mariano, huérfano de padre y de cuya crianza y educación se hizo cargo su madre, está hecho no sólo un ignorante sino un vicioso que ha comprometido su patrimonio con sus locos gastos. Doña Dominga, la madre, pretende aplacar el disgusto del tío anunciándole el matrimonio del mozo con Flora, hija de Alfonso, un rico caballero granadino y amigo del difunto esposo de doña Dominga:

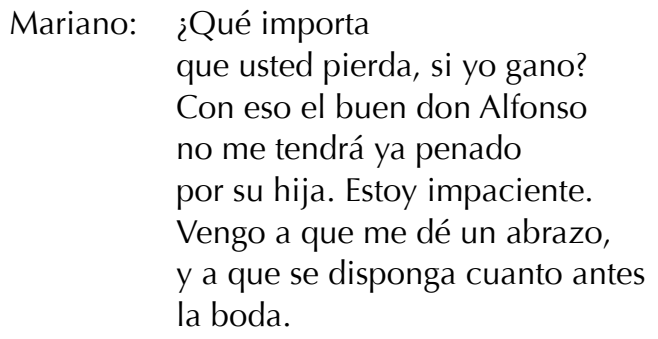

(Iriarte 2010, act. I, esc. VIII: 274)

Estructura Iriarte el resto de su comedia sobre la acumulación de impedimentos para que dicho enlace se celebre. Esta carrera de obstáculos ralentiza la llegada del desenlace y va creando el clímax dramático que provoque la resolución del conflicto, a la par que mantiene viva la curiosidad del espectador por saber el final del texto. Esto es justo lo que queremos comprobar; a saber: si este conjunto de trabas que aumentan 
la complejidad de la trama son las justas y necesarias o, por el contrario, sobran algunas, sin las cuales el ritmo en el desarrollo de la acción dramática no se vería frenado más de lo necesario. El primer equívoco que pone freno a las aspiraciones de Flora para casarse con Mariano es el descubrimiento del retrato de doña Mónica — dama embaucadora que pretende los favores de Mariano- en la faltriquera de éste:

$$
\begin{aligned}
& \text { Mariano: Yo la tomé sin malicia, } \\
& \text { la guardé en la faltriquera, } \\
& \text { la saco ahora y la veo } \\
& \text { que las cajas compañeras } \\
& \text { hicieron que, equivocada } \\
& \text { doña Mónica, me diera } \\
& \text { su retrato por el tuyo. }
\end{aligned}
$$

(acto II, esc. III: 297-298)

Un error que indigna a Flora y le hace sospechar del amor que Mariano dice profesarle:

$$
\begin{array}{ll}
\text { Flora: } & \text { Sí, señor. Muy fácil fuera } \\
& \text { si, ya que esa dama usó } \\
& \text { de amorosa estratagema } \\
& \text { para entregar su retrato } \\
& \text { a quien sabe que le aprecia, } \\
& \text { no hubiera puesto después } \\
& \text { el mío en manos ajenas. }
\end{array}
$$

(acto II, esc. III: 298)

El segundo impedimento consiste en la promesa formal de matrimonio que Mariano le ha firmado a doña Mónica. Ésta presenta el contrato matrimonial a doña Dominga, que ignora por completo la doble vida de su hijo: "Mónica (Sacando y mostrando a Dña. Dominga un papel): ¿Quién ha firmado este papel? / Dominga: Ésa es letra de mi hijo" (acto II, esc. VII: 307). Añade Iriarte otro impedimento más: el incorregible comportamiento de Mariano, quien pese a la prohibición de su tío de no pisar la casa de juego que regenta doña Mónica —nombre bajo el que se oculta Antoñuela, posadera granadina afincada en Madrid - se deja arrastrar por su afi- 
ción al juego y quebranta el mandado de don Cristóbal para satisfacer los deseos de aquélla: "Mariano: me pones en un aprieto / Si salgo de casa, el tío / rabiará. Será un infierno / Pero ¿no es fuerte rigor? / ¡Hoy cabalmente que tengo / cien doblones! / ¡Y saber que allá os estáis divirtiendo!” (acto III, esc. I: 327). Un modo de proceder que no sólo saca de quicio a Flora, sino que provoca el desenlace de la pieza, pues pillados infraganti en la práctica de una actividad ilícita, el juez sentencia a Mariano con multa y destierro: "Cristóbal: Nada sirven ya lamentos / el juez le desconoció / por el traje; más sabiendo / quién era, vino a decirme / que la multa y el destierro / de que no deben librarse / los viciosos en tal juego / habrán de comprehender / a ese mozo sin remedio" (acto III, esc. última: 358). Pone fin Iriarte a su comedia con la correspondiente apostilla moral, pues se trata de que el espectador escarmiente en cabeza ajena: "Cristóbal: No es mala señal. Con eso / si algún día tienes hijos, / les citarás este ejemplo; / y si no los instruyeres / con mejores documentos, / esto que hoy pasa por ti / pasará también por ellos" (acto III, esc. última: 363).

Nos presenta Iriarte en esta pieza un plan lineal en el desarrollo de la acción, la cual avanza al ritmo pausado que marcan los acontecimientos. El autor ejecuta a la perfección un plan previamente trazado, sin necesidad de complicar la trama mediante acciones paralelas. Todos los incidentes que hacen inviable el casamiento de Flora con Mariano están perfectamente ajustados, de tal modo que el clímax dramático alcance su punto álgido justo cuando la conducta del señorito mimado alcance un punto de no retorno: la deshonra para su tío y su madre y su destierro al proceder como un calavera.

Por lo que respecta al dibujo de los caracteres, Iriarte se esmera en perfilar el de doña Dominga, causa principal de la perdición de su hijo. Con dicha pintura el autor demuestra que ha conocido y observado a más de un niño mimado en las familias de la alta sociedad que él frecuenta. Ya en su Plan de la Comedia "El señorito mimado", doña Dominga queda descrita como una madre "contemplativa, buenaza, ignorante y llena de preocupaciones" (fol. 8). Se trata de una mujer de la clase burguesa, que no ha recibido una educación de altura, por lo que es "una muñeca muy linda con cabeza de cartón" (fol. 20). En ella despliega Iriarte una completa pintura psicológica de la inmadurez emocional y de la inutilidad 
para los asuntos prácticos. Con el mismo acierto dibuja Iriarte a Mariano, modelo del petimetre que se mueve en todo momento por sus caprichos y que no repara en el daño que sus actos producen en sus seres queridos. Se trata de un ser irresponsable y un producto del consentimiento materno. En esta comedia se aprecia una clara división entre los personajes racionales: don Cristóbal, don Alfonso, don Fausto, y los irracionales: doña Dominga y Flora. División que "ofrece un contraste muy elemental, a la par que la dedicación del hombre de la razón a las actividades sociales se pone de relieve con todo rigor. El hombre de influencias no tiene finalidad útil alguna a menos que contribuya con su esfuerzo a la sociedad en la que vive" (Glendinning 1972: 209).

Es hora de ocuparnos de Gorostiza y su comedia Contigo pan y cebolla (1833), la cual "es considerada como una de las notables sátiras del romanticismo. Constataremos que desde el punto de vista formal comparte con Las costumbres de antaño los recursos propios del figurón y en tipo de trama que es su origen, esto es, la trama falsa o intriga para escarmiento, todo lo cual la acerca a la farsa por su tono grotesco" (Reyes Palacios 2008: 74). Hablamos de una comedia en cuatro actos y prosa, estrenada el 7 de julio de 1833, en el Teatro del Príncipe. El argumento de la pieza "es sencillo, casi pueril" (Larra 1833). Matilde, hija de don Pedro, vive en la casa paterna disfrutando de todo tipo de comodidades. Ella dice estar enamorada de Eduardo, joven rico, pero de hecho rechaza cualquier contacto amoroso con él — por más que cuente para ello con la aprobación paterna-, pues ella se deja arrastrar por el ideal del amor romántico que ha creado en su imaginación tras leer novelas sentimentales y lacrimosas. Por su parte, Eduardo crea un engaño para demostrar a Matilde las incongruencias del amor idealizado que ella encarna. Ideal que dictamina que es en la pobreza y en la estrechez monetaria donde ha de surgir el verdadero amor: "Matilde: Porque ni entonces quise, ni ahora quiero oír hablar de intereses ni parentescos. Eso queda para los monstruosos enlaces que se dan por ahí, en donde todo se ajusta como libra de peras [...] No, Eduardo, no; yo le quiero a usted más que a mi vida, pero sólo por usted, créame, por usted solo" (Gorostiza 1922, acto I, esc. III: 7-8). Este es el primer impedimento que frena el desarrollo normal de la acción, el enfrentamiento entre dos concepciones del amor: la romántica y la con- 
vencional o material. Aquí encontramos la primera diferencia entre el texto de Iriarte y el de Gorostiza. En el primero el primer obstáculo consiste en la interposición de doña Mónica en el amor que se profesan Mariano y Flora, mientras que en el segundo, la acción no puede progresar porque Matilde se empeña en que Eduardo le demuestre que no es el dinero ni las comodidades los que le inducen a amarla. Con esta oposición de Matilde a aceptar un pretendiente acaudalado, la joven da al traste con la proposición de matrimonio apalabrada entre don Pedro y Eduardo, a la par que deja muy claras sus intenciones: "Matilde: Perdone usted, padre mío; yo no puedo en la agitación en la que estoy ni decidir ni consentir en nada... ya lo pensaré... ya lo consultaré a mí misma" (acto I, esc. VIII: 25). Ésta es otra diferencia notable entre ambas comedias, pues en El señorito mimado el encadenado de obstáculos que paralizan el devenir de la acción son elementos tangibles y materiales —en esencia la vida disoluta y depravada de Mariano- mientras que en Contigo pan y cebolla los impedimentos son mentales e ideológicos. Diferencia que se explica porque Gorostiza tiene un propósito no sólo didáctico, sino que se propone criticar el romanticismo lacrimoso, cuyos aspectos teóricos ya habían sido censurados en Las costumbres de antaño (1819).

¿Y cómo acabar con este atasco que paraliza la acción? Gorostiza usa su ingenio para dar vueltas a esta situación mediante la llamada "trama fingida" o "comedia dentro de la comedia". Si Matilde no admite como pretendiente a Eduardo por ser rico habrá que buscar el engaño más apropiado para hacerlo pasar por pobre y menesteroso: “Eduardo: ¡Pobre de mí, a qué me veo forzado para obtener a Matilde [...] engañarla, fingir un carácter tan opuesto al mío!" (acto II, esc. VI: 26). El engaño consiste en hacer creer a Matilde que Eduardo ha sido desheredado por su tío y que se encuentra en la miseria. Matilde muerde el anzuelo y sin contar con el consentimiento paterno se casa en secreto con Eduardo. Ambos dejan la casa paterna y se trasladan a una buhardilla inmunda, privados de todo tipo de lujos. Para poder subsistir ella trabaja como costurera y él como escribano. Pero tan pronto Matilde se percata de lo dura que es la vida del pobre, la que antes fuera calificada por su amado como "una hembra extraordinaria [...] una heroína de novela" (acto III, esc. III: 37) reniega de sus sueños románticos, tras comprobar lo que comporta su idílico amor 
a la pobreza: "Matilde: ¿También tendré que barrer mañana? D. Eduardo: Todos los días ja ti te gusta tanto la limpieza!, y tendrás asimismo que guisar, fregar, jabonar, planchar, coser, remendar y hacer, en fin, todo aquello que hace una mujer casada sin criada" (acto IV, esc. V: 57). A partir de este momento se acelera el ritmo de la acción, pues Matilde, tras probar lo dura que es la vida del pobre, pone los pies en el suelo. Acude don Pedro al rescate de su hija, le perdona su fuga del hogar paterno y el que se casara sin su permiso. Matilde accede a los requerimientos paternos de dejar atrás la vida mísera, pues ha escarmentado al comprobar lo nefasto que puede ser dejarse llevar por los sueños y anhelos románticos “D. Eduardo: Oye; Matilde, ¿y no es cierto que lo que a ti te acomoda es vivir tranquila en un rincón como este, y comer conmigo pan y cebolla? / Dña. Matilde: Si la cebolla no me recordara siempre que la como [...] luego, Eduardo, hazte cargo [...] ¿podemos acaso desairar a papá, cuando se muestra tan bondadoso?" (acto IV, esc. última: 65). A diferencia de El señorito mimado, en la que Iriarte provoca el desenlace de la acción mediante la ruptura del compromiso matrimonial entre Flora y Mariano, en Contigo pan y cebolla Gorostiza ingenia una solución al conflicto dramático que se basa en la redención o cambio de actitud de Matilde, que pasa de ser una ingenua jovencita romántica a una mujer realista porque ha aprendido una lección: que de los sueños no se vive. Es decir, Gorostiza mejora el desenlace mecánico y previsible que Iriarte idea para su comedia, pues pone en escena un final menos moralizante y más pragmático y realista, acorde con las críticas a los perjuicios del romanticismo facilón y sentimental que impregna toda su obra.

En lo que atañe al dibujo de los caracteres nos centramos en Matilde, la cual es una más de las muchas damas europeas dadas al "gusto romántico" y que en España debían su existencia a la penetración en masa de las novelas románticas "pues a fin de cuentas Contigo pan y cebolla más que una reacción a una situación familiar, constituye un comentario satírico de cierto grupo de la sociedad de su tiempo y de la novela romántica de importación, llevado a cabo por medio de lo que Gorostiza creyó debía ser el teatro y de su lectura e interpretación cervantinas" (Temprano 1995: 155). En contraposición a las manías románticas de Matilde, Gorostiza nos presenta a Eduardo — quien, en justicia, es el protagonista—, un joven 
realista que sabe lo mucho que se juega de no conseguir su propósito. A diferencia de lo que ocurre en El señorito mimado, nuestro autor recurre a la oposición entre caracteres fuertes: don Pedro y Mariano, frente a los débiles: Matilde. Una contraposición mediante la que pretende que el espectador se percate de que las personalidades débiles lo tienen difícil en una sociedad pragmática en la que priman los valores materiales.

\subsection{Análisis del grado de acierto y habilidad en el uso de los engaños}

En el caso de Contigo pan y cebolla, el engaño no tiene tanta importancia en el planteamiento como en el nudo de la acción. Gorostiza pretende criticar el comportamiento de mujeres como Matilde, que rechaza sin razón alguna a su galán. El rechazo supone la reacción del galán desdeñado, lo que provoca la aparición de los engaños en el nudo de la acción. Un ejemplo de ello lo tenemos en el acto II: Eduardo reflexiona sobre el engaño lamentándose de tener que acudir a él para conseguir a su amada:

DON EDUARDO. Si esto no la ablanda, digo que es de piedra barroqueña $[\ldots]$ ¡pobre de mí, y a lo que me veo obligado para obtener a Matilde! [...] a engañarla, ¡a fingir un carácter tan opuesto al mío! (59).

Partiendo de este ejemplo, procedemos a comprobar el nivel de acierto y el grado de pericia de Iriarte y de Gorostiza en el uso del engaño como herramienta para crear situaciones de enredo en la trama, dotar a la acción de intriga, provocar equívocos y lograr el desenlace deseado. En el caso de El señorito mimado, la naturaleza del engaño está relacionada con la habilidad de Mariano para nadar y guardar la ropa: finge estar enamorado de Flora, pero al mismo tiempo se deja embaucar por Mónica. En esta obra, Iriarte ofrece una concatenación de engaños que es bien conocida por el público, lo cual ayuda al espectador a seguir el desarrollo de la acción. Así, Mariano engañado por Mónica intenta, en el acto II, engañar a Flora afirmando que tiene un retrato de ella bien guardado, cuando en realidad es Flora quien tiene en casa su propio re- 
trato (Iriarte 2010: 295-299). En el acto III, Mónica entra en secreto a la casa de Mariano (325-326) y le dice que le entrega una carta en la que él le había dado palabra de matrimonio, pero de facto le engaña, pues tal misiva es una falsificación de la que Fausto le ha escrito a Flora diciéndole lo mucho que la ama (328). En definitiva, en esta obra los engaños de Mónica son consecutivos y no coincidentes en el tiempo con los engaños de otros personajes. Se trata de una planificación lineal de los engaños que no añade complejidad a la trama, ni complica ni retarda el desenlace. Sigue Iriarte en el uso del engaño las pautas marcadas por Moratín padre.

En Contigo pan y cebolla, Gorostiza determina la trama de su pieza sobre un engaño único que abarca toda la obra: Matilde jamás quiso vivir en la indigencia, pensamiento tan sólo propio de una jovencita romántica pero nada práctica: “Eduardo: Ya que Matilde, sólo por vivir con su padre y por disfrutar a su lado de las ruines comodidades de la vida, sacrifica magnánimamente todos los placeres de la indigencia" (Gorostiza 1922, acto IV, esc. última: 66). Y el engaño que practica Matilde tan sólo puede ser desenmascarado con otro más sutil: la "trama fingida", o cómo engañar al engañador. Gorostiza ingenia una trampa para lograr que Matilde descubra sus verdaderas convicciones: Eduardo finge haber sido desheredado por su tío, los amantes pasan a vivir en la pobreza y cuando la miseria aprieta, Matilde abdica de sus sueños románticos. Mediante el uso de la "trama fingida", Gorostiza complica el desarrollo de la acción y se aparta del modelo irartiano en el uso de los engaños. En su caso el engañador cae en la trampa de su propio engaño al recurrir al "engaño invertido".

\subsection{Ecos y críticas en la prensa sobre el grado de éxito de ambas comedias}

Otro de los parámetros que nos ayudan a mostrar en qué medida Gorostiza supera en Contigo pan y cebolla el corsé del modelo neoclásico de "comedia de buenas costumbres" practicado por Iriarte en El señorito mimado, nos viene de la mano de la crítica en la prensa a ambas comedias. La pieza de Iriarte logró acariciar el éxito en su estreno, pero tal éxito no fue duradero. De entrada la crítica la tacha de nada original, "el plan es 
una bagatela y se tomó de Goldoni" ${ }^{10}$ En segundo lugar, se tilda a su autor de carecer de iniciativa al seguir al pie de la letra los dictados de Moratín: "sin numen bien sabe usted que no se producen más que abortos, y cuando más una heladez como El señorito mimado, cuyo mérito confieso a usted no acierto a descubrir". ${ }^{11}$ Justo cuarenta y cinco años después se estrenó Contigo pan y cebolla y el público dictaminó a favor del autor: "el señor Gorostiza, poeta ya ventajosamente conocido en nuestro teatro moderno, se ha apoderado de una idea feliz y ha escogido un asunto de mayor importancia, y lo ha desempeñado con el acreditado talento que nos había prometido". ${ }^{12}$ Una crítica favorable que también es comentada por otros cronistas: "se ha presentado con mucho aplauso la comedia nueva de don Manuel de Gorostiza, titulada Contigo pan y cebolla. El autor de Indulgencia para todos ha hecho girar su linda comedia sobre las bodas desatinadas a que suele el amor arrastrar a algunas desdichadas jóvenes, cuya romántica cabeza ha exaltado la lectura de novelas". ${ }^{13}$ Sin embargo, fue Mariano José de Larra quien criticó con más extensión y conocimiento esta pieza. Fígaro repasa con detalle cada uno de sus posibles defectos, pero

a pesar de estas observaciones, que no podemos menos de hacer, nos complacemos en repetir que es mayor la suma de las bellezas que la de los defectos de la comedia. El señor Gorostiza ha adquirido un nuevo laurel y nosotros quisiéramos que la obligación del periodista se limitase a alabar: mucho nos daría que hacer aun en este caso esta composición dramática. En cuanto a la representación, podemos asegurar que no recordamos haber visto en Madrid nada mejor desempeñado en este género (Larra 1833: 702).

Tampoco podemos olvidarnos de que Manuel Bretón de los Herreros terció en el debate promovido por Ángel Pedro de Gorostiza a propósito del mérito de la obra de su hermano: “¿Hay razón para acusarnos de mala

10 Diario de Madrid (19 de octubre de 1788): 1 en ejemplar y 703 en la paginación de la serie.

11 J. M. de F. en Semanario Zaragozano (19 de abril de 1879): 2 y 242 en paginación de la serie.

12 Revista Española. Madrid (9 de julio de 1833): 7, y 701 en paginación de la serie.

13 El Correo de las Damas. Madrid (10 de julio de 1833): 9 y 15 en paginación en serie. 
fe y parcialidad sólo porque no hemos dicho que Contigo pan y cebolla es la más perfecta comedia escrita y por escribir como pretende su merced? No nos tenemos por infalibles: pero a personas más inteligentes en la materia que nuestro antagonista, les ha parecido nuestro razonado y decoroso juicio de la comedia Contigo pan y cebolla muy conforme a las leyes del buen gusto y la sana crítica" (Bretón 1833: 6) Resulta evidente que en igualdad de oportunidades la pieza de Gorostiza tuvo mayor repercusión que la de Iriarte, no sólo en cuanto al éxito de público y número de representaciones, sino en lo que atañe a los juicios de la crítica especializada. El texto de Gorostiza apuesta por impulsar un cambio ideológico en el espectador, mientras que la comedia irartiana enfatiza el mensaje moral y la propuesta didáctica.

\section{Conclusiones}

Al inicio de la presente colaboración nos propusimos demostrar que Manuel Eduardo de Gorostiza en modo alguno debía ser considerado un dramaturgo menor, surgido a la sombra de los autores de renombre del periodo neoclásico español. Para dar cuerpo a tal demostración hemos desplegado toda una batería de pruebas, cuyos resultados evidencian que el autor nada tiene que envidiar a aquéllos; más en concreto a Tomás de Iriarte. Ha quedado claro que Gorostiza sabe muy bien lo que se trae entre manos, pues ha estudiado a fondo tanto el teatro español, en general, como los problemas que afectan a la praxis teatral hispana en el periodo ilustrado, en particular. Además nuestro autor cuenta con su propia concepción del drama y de la comedia, un soporte teórico que aplicará en la composición de sus piezas. Del mismo modo, Gorostiza marca diferencias con la factura de las comedias neoclásicas al uso e imprime en Contigo pan y cebolla su propio genio dramático. Este extremo ha quedado demostrado mediante un análisis contrastivo de aquélla con El señorito mimado, de Iriarte. Tanto en el desarrollo de la acción y en la pintura de los caracteres, como en el uso del engaño, Gorostiza mejora la propuesta dramática irartiana y se sirve del molde de la "comedia de buenas costumbres" para ensayar un nuevo formato de comedia, más acorde con el pensamiento liberal de los prerrománticos. En dicho formato se recurre a otros 
procedimientos para complicar la trama, se dota a los personajes de una frescura, vitalidad y pasión sentimental que no se dan en el texto irartiano.

$Y$ para corroborar que nuestras premisas son ciertas, acudimos a los juicios y críticas imparciales de los expertos y cronistas. Queda patente que, sin menoscabo del interés que en sus días suscitara El señorito mimado, Contigo pan y cebolla fue seguida más al detalle por la crítica teatral, provocó un mayor grado de polémica entre los expertos y dio pie a que se replantease la inmovilidad por la que se regía la comedia neoclásica a finales del XVIII y comienzos del XIX.

\section{Bibliografía}

Álvarez Franco, María Magdalena. El recurso del engaño en el teatro neoclásico español. Tesis doctoral. Cáceres: Universidad de Extremadura, 2013.

Bretón de los Herreros, Manuel. "Al seudónimo defensor de la comedia Contigo pan y cebolla", en El Correo de Madrid (12 de agosto de 1833): 6.

Carnero, Guillermo. "Los dogmas neoclásicos en el ámbito teatral", en Estudios sobre el teatro español del siglo XVIII. Zaragoza: Publicaciones Universitas, 1997.

DIARIO DE MADRID (19 de octubre de 1788): 1.

El Correo de las Damas (10 de julio de 1833): 9.

F. J. M. DE. Semanario Zaragozano (19 de abril de 1879): 2.

Fernández de Moratín, Nicolás. "Discurso preliminar", en Obras de Don Nicolás y de Don Leandro Fernández de Moratín. Madrid: Atlas, 1944. 307-325.

Glendinning, Nigel. Historia de la Literatura Española. Siglo XVIII. Vol. 4. Barcelona: Ariel, 1972.

Gorostiza, Manuel Eduardo de. "Decline of Ancient Theatre", en New Montly Magazine and Literary Journal. London. Vol. X, art. 1º, 1824a. 328-333.

Gorostiza, Manuel Eduardo De. "Modern Spanish Theatre", en New Montly Magazine and Literary Journal. London. Vol. X, art. 20, 1824b. 502-506.

Gorostiza, Manuel Eduardo De. "Modern Spanish Theatre", en New Montly Magazine and Literary Journal. London. Vol. X, art. 3º, 1824c. 87-92.

Gorostiza, Manuel Eduardo de. "Culteranismo", en Armando de María y Campos. Manuel Eduardo de Gorostiza y su tiempo: vida y obra. México: Talleres Gráficos de la Nación, 1959a. 398-407.

Gorostiza, Manuel Eduardo de. "Reflexiones sobre el antiguo teatro español", en Armando de María y Campos. Manuel Eduardo de Gorostiza: vida y obra. México: Talleres Gráficos de la Nación, 1959b. 408-415.

IRIARTE, TOMÁs DE. El señorito mimado, en Teatro original completo. Ed. P. Sebold. Madrid: Cátedra, 2010.

IRIARTE, TOMÁs DE. Plan de la Comedia "El señorito mimado". Biblioteca Nacional. Sig: MSS/7922. 
Larra, Mariano José de. "Contigo pan y cebolla", en Revista Española, 75 (9 de julio de 1833): 701-702.

María y CAmpos, ARmando De. Manuel Eduardo de Gorostiza y su tiempo: vida y obra. México: Talleres Gráficos de la Nación, 1959.

Mora, José JoAquín De. "Moral", en Crónica Científica y Literaria, núm. 211 (6 de abril de 1819): folio 3.

Ortuño Martínez, Manuel. "Manuel Eduardo de Gorostiza, hispano-americano, romántico y liberal", en Cuadernos Hispanoamericanos, núm. 456-457 (1988): 105-120.

Redding, Cyrus. "Manuel Eduardo de Gorostiza", en Reminiscences and Mamoirs of Thomas Campbell. Ed. Charles Skeel. London: X (1860): 318-321.

Reyes Palacios, FeliPe. "La polémica del romanticismo en Manuel Eduardo de Gorostiza", en FALL (Latin American Theatre Review). Vol. 42, 1 (2008): 67-80.

Reyes Palacios, FeliPe. Manuel Eduardo de Gorostiza en su contexto dramático. México: Universidad Nacional Autónoma de México, 2009.

REVISTA ESPAÑOLA (9 de julio de 1833): 7.

RodríGuez SÁnCHeZ de LeÓn, MARía José. La crítica dramática en España (17891833). Madrid: Consejo Superior de Investigaciones Científicas, 1999.

Roso DíAz, José. "Vestimenta, moda y sociedad en la comedia española de buenas costumbres", en Estudios Humanísticos. Historia, 15 (2016): 157-177.

SuÁRez RADILlo, CARLOS MANUEl. El teatro neoclásico y costumbrista hispanoamericano. Madrid: Instituto de Cooperación Iberoamericana, 1984.

Temprano, Juan. "Contigo pan y cebolla: una caricatura dramática del primer romanticismo", en Teatro. Revista de Estudios Culturales, 6-7 (1995): 151-161.

Usıgl, Rodolfo. "Escritos sobre la historia del teatro en México", en Teatro completo de Rodolfo Usigli. México: Fondo de Cultura Económica, 2015. Disponible en: <https://books.google.es/books?id=8lsWDQAAQBAJ\&printsec=fron tcover\&hl=es $\# \mathrm{v}=$ onepage \&q\&f$=$ false $>$.

Víctor Cantero García

Es Licenciado en Filología Hispánica por la Universidad de Zaragoza y Doctor en Filología Hispánica por la Universidad de Cádiz. Se encuentra adscrito al Departamento de Filología y Traducción de la Universidad Pablo Olavide como profesor colaborador y es miembro del grupo de investigación "Sociolingüística andaluza". 